\title{
Prevalência de anticorpos IgG antiparvovírus B19 em gestantes durante 0 atendimento pré-natal e casos de hidropisia fetal não imune atribuídos ao parvovírus B19, na Cidade do Rio de Janeiro
}

\author{
Anti-parvovirus B19 IgG antibody prevalence in pregnant women during antenatal \\ follow-up and cases of non-immune hydropsis fetalis due \\ to parvovirus B19, in the City of Rio de Janeiro
}

\author{
André Ricardo Araujo da Silva ${ }^{1,2}$,Susie Andries Nogueira², Júlio Cezar Laura Alzeguir ${ }^{1}$, \\ Maria Célia Freitas Leite da Costa ${ }^{1}$ e Jussara Pereira do Nascimento ${ }^{3}$
}

\begin{abstract}
RESUMO
Com o objetivo de medir a prevalência de anticorpos IgG contra o parvovírus B19 em gestantes com até 24 semanas de idade gestacional e detectar a ocorrência de casos de hidropisia fetal não-imune atribuídos a esse vírus, coletamos 249 amostras de soro em uma maternidade de referência na Cidade do Rio de Janeiro, entre junho de 2003 e março de 2005. As gestantes foram acompanhadas até o termo da gestação, sendo detectados 17 casos de hidropisia fetal. Quatro casos foram atribuídos ao parvo vírus B19 e dois destes ocorreram em gestantes residentes na zona oeste da cidade, em fevereiro de 2005. Resultados positivos para anticorpos IgG antiparvovírus B19 foram encontrados em 172 ( 71,6\%) gestantes (IC 95\% 65,5-77,7\%), sendo esta prevalência de anticorpos comparável à encontrada em outras cidades brasileiras. A única variável associada com aquisição prévia de anticorpos IgG foi número de gestações anteriores maior que um( $\mathrm{p}=0,02$, IC 95\% 0,36-0,94).
\end{abstract}

Palavras-chaves: Parvovírus B19. Gestação. Anticorpos IgG. Hidropisia fetal não imune.

\begin{abstract}
With the aim of measuring the prevalence of anti-parvovirus B19 IgG antibodies during pregnancy up to 24 weeks of gestation and detecting cases of nonimmune hydrops fetalis, 249 sera from pregnant women attending a reference hospital in Rio de Janeiro City, from June 2003 to November 2004 were collected. They were followed-up until the end of pregnancy, with 17 cases of fetal hydrops detected. Four cases were caused by parvovirus B19 and two of them occurred in pregnant women living in the western zone of the city, during February 2005. Anti-parvovirus B19 IgG antibodies were found in 172 (71.6\%) pregnant women (CI 95\% 65.5\%-77.7\%); this antibody prevalence is similar to results found for others Brazilian cities. The only variable associated with previous acquisition of IgG antibodies to parvovirus $B 19$ was number of pregnancies greater than one ( $\mathrm{p}=0.02$, CI $95 \%$ 0.36-0.94).
\end{abstract}

Key-words: Parvovirus B19. Pregnancy. IgG antibodies. Nonimmune hydrops fetalis.

\footnotetext{
1. Instituto Fernandes Figueira da Fundação Oswaldo Cruz, Rio de Janeiro, RJ. 2. Hospital Universitário Clementino Fraga Filho da Universidade Federal do Rio de Janeiro, Rio de Janeiro, RJ. 3. Instituto Biomédico da Universidade Federal Fluminense, Niterói, RJ.

Financiado através de recursos da FIOCRUZ e do projeto CNPq 520897/96-0.

Endereço para correspondência: Dr. André Ricardo Araújo da Silva. Rua Mariz e Barros 76/302, Tijuca, 20270-000 Rio de Janeiro, RJ.

Tel: 5521 3973-7858.

e-mail:andrericardo@ hucff.ufrj.br

Recebido para publicação em 31/10/2005

Aceito em 26/8/2006
} 
0 parvovírus humano B19 (PB19) foi descrito inicialmente em 1975, por Cossart e cols, em doadores de sangue assintomáticos e desde então vem sendo relacionado a várias entidades clínicas como a crise aplástica transitória, 0 eritema infeccioso (EI) e a hidropisia (HF) e morte fetais ${ }^{27}$. A infecção por parvovírus B19 tem sido descrita em todas as partes do mundo onde foi pesquisada, manifestando-se primariamente como surtos de eritema infeccioso em crianças pré-escolares e adolescentes. Durante os surtos de EI, adultos suscetíveis podem ser infectados de maneira que ocorre um aumento gradual da prevalência de anticorpos IgG conforme a idade ${ }^{1319}$.

0 conhecimento da prevalência de anticorpos IgG antiB19 em gestantes é importante, pois durante a infecção aguda, o parvovírus B19 pode ser transmitido verticalmente para 0 feto, causando eventualmente morte fetal, aborto e hidropisia ${ }^{27}$. Estas complicações durante a gestação são mais freqüentemente descritas quando a infecção materna ocorre até a $20^{\text {a }}$ semana gestacional ${ }^{19}$.

Estudos de prevalência de anticorpos IgG em gestantes indicam uma variação muito grande, de 35 a 81\%, dependendo da população estudada ${ }^{345} 1622$ sendo que 0 número de casos de hidropisia fetal atribuídos ao parvovírus B19 pode aumentar em anos epidêmicos de eritema infeccioso, atingindo até 13,5\% das gestantes suscetíveis não-imunes ${ }^{6}{ }^{26}$. Gestantes cuja atividade ocupacional exige contato freqüente com crianças e que possuem filhos menores de 10 anos de idade são mais propensas à infecção aguda por parvovírus B19624.

0 objetivo deste estudo é mensurar a prevalência de anticorpos IgG para o parvovírus B19 em gestantes atendidas em uma maternidade de referência na Cidade do Rio de Janeiro e verificar a possível ocorrência de hidropisia fetal causadas pelo parvovírus B19 durante o período de estudo.

\section{MATERIAL E MÉTODOS}

Seleção de pacientes e tamanho da amostra. Durante 0 período compreendido entre junho de 2003 e novembro de 2004, foram selecionadas 240 gestantes oriundas do ambulatório de acompanhamento pré-natal do Instituto Fernandes Figueira (IFF), com idade gestacional de até 24 semanas completas, independentemente do motivo de acompanhamento, para a realização de sorologia específica para 0 parvovírus B19 e seguimento até 0 final da gestação.

A maternidade do IFF atende a gestantes tanto do município do Rio de Janeiro, quanto de municípios da área metropolitana, e é considerada como um serviço de referência para acompanhamento de gestações de alto-risco. 0 cálculo do tamanho da amostra foi baseado em estudo piloto realizado entre junho e novembro de 2003, com 46 gestantes do IFF. Neste subgrupo, 0 valor de prevalência encontrado de anticorpos IgG específicos para o parvovírus B19, foi de $69,4 \%$. Utilizamos como população geral de estudo um contigente estimado em seis milhões de habitantes residentes no município do Rio de Janeiro ${ }^{7}$, e estimamos um intervalo de confiança de $95 \%$ para uma prevalência entre $65 \%$ e $77 \%$.
Adicionalmente, foram coletadas amostras de sangue para a realização de sorologia para o parvovírus B19 de todas as 17 gestantes em acompanhamento no IFF que tiveram 0 diagnóstico de hidropisia fetal (HF) pela ultra-sonografia. Nove amostras de casos de hidropisia foram coletadas após novembro de 2004, não sendo incluídas na análise da prevalência de anticorpos IgG. 0 diagnóstico definitivo da causa da hidropisia fetal foi estabelecido por exames sorológicos de rotina do pré-natal, cariótipo fetal e análise de placenta e tecidos fetais por histologia convencional e para pesquisa para parvovírus B19 por hibridização in situ e PCR.

Armazenamento das amostras e testes sorológicos. 0 soro obtido das gestantes foi mantido congelado a $-20^{\circ} \mathrm{C}$ até a análise da amostra. 0 teste utilizado para a pesquisa de anticorpos anti-B19 foi o ensaio imunoenzimático ELISA (BiotrinInternational, Irlanda) . 0 teste de detecção de anticorpos IgG é capaz de detectar de 3 a 5UI/ml do padrão de IgG ( International Standard, National Institute for Biological Standards and Control, Reino Unido) e apresenta 100\% de sensibilidade e especificidade de $100 \%$, conforme informado pelo fabricante. 0 teste de detecção de anticorpos IgM apresenta $86 \%$ de sensibilidade e $100 \%$ de especificidade. A positividade para IgG foi considerada como infecção pregressa, indicando proteção contra o parvovírus B19. As pacientes IgG negativas foram consideradas suscetíveis à infecção. As gestantes com diagnóstico de $\mathrm{HF}$ e anticorpos IgM para o parvovírus B19 foram consideradas como tendo infecção aguda pelo vírus. Nas gestantes em que 0 teste de IgM apresentou valores limítrofes ( não conclusivo) e 0 teste de IgG foi negativo, o B19 foi excluído como causa da hidropisia. Porém, quando 0 teste de IgG foi positivo, o B19 não pôde ser excluído como causa provável da hidropisia.

Variáveis analisadas. As gestantes imunes ao vírus foram comparadas com as não-imunes, em relação a possíveis variáveis para a aquisição prévia da infecção como município de origem, idade materna, número de gestações anteriores, número de filhos, convívio com crianças por mais de 4 horas por dia e convívio com filhos menores de 10 anos. Os dados coletados foram analisados através do programa EPI-INFO 6.0 (CDCAtlanta). 0 teste do qui-quadrado e 0 teste de Fischer foram utilizados para avaliar associações entre as gestantes imunes e aquelas suscetíveis. Um valor de $p<0,05$ foi considerado como de significância estatística e intervalos de confiança foram calculados para as variáveis estudadas. Este projeto foi submetido e aprovado pelo comitê de ética e pesquisa da instituição (Instituto Fernandes Figueira, Fundação Oswaldo Cruz).

\section{RESULTAD0S}

Antecedentes obstétricos. Aidade média das gestantes foi de 29,7 anos (variação de 14 a 45 anos), sendo $28 \mathrm{com}$ idade entre 11 e 20 anos, 101 com idade entre 21 e 30 anos, 89 com idade entre 31 e 40 anos e 22 com idade maior que 41 anos. Cento e cinqüenta e três $(63,4 \%)$ gestantes eram oriundas do município do Rio de Janeiro e $85(35,7 \%)$ de outros municípios da região metropolitana. Do total de 
grávidas, 51 (21,8\%) eram primigestas e 0 número médio de filhos foi de 1,2. A maior (73,1\%) parte das gestantes iniciou 0 pré-natal antes da 15aㅗ semana (média de 13 semanas e 3 dias) e a idade gestacional média no momento da coleta da amostra de soro foi de 15 semanas e 3 dias. A Tabela 1 mostra a idade gestacional no momento da coleta do soro. Em relação aos antecedentes obstétricos, foram relatados história prévia de prematuridade em $73(30,7 \%)$ gestantes, hidropisia fetal em 6 (2,5\%) e malformação fetal em 36 (15,1\%). Em relação ao motivo de encaminhamento ao IFF, encontramos necessidades especiais para as mães em $54,5 \%$ e necessidade de cuidados relacionados ao feto ou alterações fetais em gestações prévias em $45,5 \%$.

Tabela 1- Idade gestacional na coleta de sorologia IgG para parvovírus B19.

\begin{tabular}{lrr}
\hline & \multicolumn{2}{c}{ Gestantes } \\
\cline { 2 - 3 } Idade gestacional na coleta (semanas) & \multicolumn{1}{c}{$\mathrm{n}^{0}$} & $\%$ \\
\hline $0-8$ & 147 & 3,3 \\
8-16 & 85 & 35,3 \\
16-24 & 240 & 100,0 \\
\hline Total
\end{tabular}

Prevalência de anticorpos IgG anti-B19. 0 percentual de grávidas positivas para IgG antiparvovírus B19 em todas as faixas etárias foi de 71,6\% (172), sendo 28,4\% (68) suscetíveis à infecção. A prevalência de anticorpos IgG foi de $57,1 \%$ na faixa etária entre 11 e 20 anos, 71,2\% na faixa etária entre 21 e 30 anos, 76,4\% na faixa etária entre 31 e 40 anos e 72,7\% entre as gestantes acima de 41 anos. Não houve diferença estatisticamente significativa entre a prevalência de anticorpos IgG entres as gestantes residentes no município do Rio de Janeiro $(68,8 \%)$ e aquelas de outros municípios (76,7\%) $p=0,15$ (IC 95\% 0,721,06). Foi possível coletar nova amostra de sangue para dosagem de anticorpos IgG no terceiro trimestre da gestação em apenas 8 (11,7\%) das 68 gestantes inicialmente IgG negativas, não sendo detectada soroconversão em nenhuma delas.

Sinais clínicos, fatores de risco maternos e ocupacionais para a aquisição de infecção pelo parvovírus B19. Entre as gestantes, 110 (46,2\%) possuíam atividades ocupacionais com contato freqüente com crianças, $90(37,5 \%)$ relatavam ter mais de um filho no domicílio e $89(37,4 \%)$, filhos menores de 10 anos em seus domicílios. Nenhuma das gestantes relatou contato com portadores de eritema infeccioso ou sintomas ou sinais clínicos compatíveis com a infecção pelo parvovírus B19 como exantema ou artralgia, durante o período de estudo.

As variáveis estudadas que pudessem estar associadas positivamente à aquisição prévia da infecção pelo parvovírus B19, entre os grupos considerados imunes e não imunes ( IgG positivo e IgG negativo) são mostradas na Tabela 2. A única variável que demonstrou associação positiva com aquisição de anticorpos IgG prévios à gestação atual foi gesta maior que 1 ( $p=0,02$ IC $95 \% 0,36-0,94$ ). Uma outra variável com tendência de associação positiva foi ter idade maior que 20 anos ( $p=0,05$ IC $95 \%$ 0,27-1,01). Não foram encontradas associações positivas para todas as outras variáveis estudadas.

Ocorrência de casos de hidropisia fetal e associação com o parvovírus B19. Foram registrados 17 casos de hidropisia fetal não-imune entre abril de 2003 e fevereiro de 2005 (Tabelas 3 e 4), sendo que 9 não estavam incluídos no estudo de prevalência de anticorpos devido à coleta de amostra para sorologia ter ocorrido após a $24^{\mathrm{a}}$ semana de

Tabela 2- Análise de fatores de risco para infecção prévia pelo parvovírus B19.

\begin{tabular}{|c|c|c|c|c|c|}
\hline Variáveis estudadas & $\begin{array}{c}\text { Gestantes IgG } \\
\text { anti-B19 } \\
\text { positivas }\end{array}$ & $\begin{array}{c}\text { Gestantes IgG } \\
\text { anti-B19 } \\
\text { negativas }\end{array}$ & Totais & Valor de $p$ & IC $95 \% *$ \\
\hline Idade $>20$ anos & 155 & 55 & 210 & 0,05 & $0,27-1,01$ \\
\hline $\begin{array}{l}\text { Convívio com crianças } \\
\text { (atividade ocupacional) }\end{array}$ & 81 & 29 & 110 & 0,66 & $0,78-1,47$ \\
\hline $\begin{array}{l}\text { Número de gestações } \\
\text { anteriores >1 }\end{array}$ & 31 & 21 & 52 & 0,02 & $0,36-0,94$ \\
\hline $\begin{array}{l}\text { Filhos menores de } \\
10 \text { anos em casa }\end{array}$ & 64 & 25 & 89 & 0,92 & $0,68-1,41$ \\
\hline $\begin{array}{l}\text { História anterior de } \\
\text { prematuridade }\end{array}$ & 53 & 20 & 73 & 0,96 & $0,66-1,56$ \\
\hline $\begin{array}{l}\text { História anterior de } \\
\text { mal formação fetal }\end{array}$ & 27 & 9 & 36 & 0,69 & $0,57-2,32$ \\
\hline
\end{tabular}

*intervalo de confiança de $95 \%$

\begin{tabular}{|c|c|c|c|c|c|c|}
\hline Gestantes & $\begin{array}{c}\text { Data de } \\
\text { diagnóstico }\end{array}$ & $\begin{array}{c}\text { Idade } \\
\text { gestacional de } \\
\text { diagnóstico* }\end{array}$ & $\begin{array}{c}\text { Idade gestacional } \\
\text { na coleta de } \\
\text { sorologia para } 0 \\
\text { B19* } \\
\end{array}$ & Sorologia B19 & Causa provável & Desfecho* \\
\hline №4 & $19 / 09 / 2003$ & $22 \mathrm{~s} 1 \mathrm{~d}$ & 23s 3d & IgM-/IgG- & Năo esclarecida & Óbito fetal com 23s 3d \\
\hline №5 & $29 / 12 / 2003$ & $25 \mathrm{~s} 6 \mathrm{~d}$ & $24 \mathrm{~s}$ & IgM-/ IgG+ & Năo esclarecida & $\begin{array}{c}\text { Prematuro 33s 4d } \\
\text { Óbito com 4d }\end{array}$ \\
\hline №6 & $07 / 01 / 2004$ & 23s 6d & $12 \mathrm{~s} 5 \mathrm{~d}$ & IgM -/ IgG- & $\begin{array}{c}\text { Incompatibilidade } \\
\mathrm{Rh}\end{array}$ & Óbito fetal com 30s $6 \mathrm{~d}$ \\
\hline №7 & $19 / 01 / 2004$ & $21 \mathrm{~s} 4 \mathrm{~d}$ & $23 \mathrm{~s} 6 \mathrm{~d}$ & $\begin{array}{l}\text { IgM borderline/ } \\
\text { IgG- }\end{array}$ & Năo esclarecida & $\begin{array}{l}\text { Vivo com alta } \\
\text { (regressão HF) }\end{array}$ \\
\hline №8 & $29 / 01 / 2004$ & $16 \mathrm{~s} 1 \mathrm{~d}$ & $15 \mathrm{~s} 3 \mathrm{~d}$ & IgM-/ IgG + & Cardiopatia & Desconhecido \\
\hline №9 & $03 / 02 / 2004$ & $15 s$ & $14 \mathrm{~s} 3 \mathrm{~d}$ & $\begin{array}{c}\text { IgM borderline/ } \\
\operatorname{IgG}+\end{array}$ & $\begin{array}{l}\text { S. Down provável } \\
\text { Parvovirus B19 }\end{array}$ & Vivo com alta \\
\hline №11 & $22 / 07 / 2004$ & $18 \mathrm{~s}$ & $16 \mathrm{~s} 3 \mathrm{~d}$ & IgM-/ IgG - & Cardiopatia & Óbito fetal com 33s $4 \mathrm{~d}$ \\
\hline No14 & $29 / 09 / 2004$ & $24 \mathrm{~s}$ & $24 \mathrm{~s}$ & IgM-/ IgG+ & Năo esclarecida & Óbito fetal com $25 \mathrm{~s}$ \\
\hline
\end{tabular}

* expresso em semanas (s) e dias (d). HF: hidropsia fetal. 
Tabela 4 - Gestantes apresentando hidropisia fetal não-imune, excluídas do estudo de prevalência e desfecho da gestação.

\begin{tabular}{|c|c|c|c|c|c|c|}
\hline Gestantes & $\begin{array}{c}\text { Data de } \\
\text { diagnóstico }\end{array}$ & $\begin{array}{c}\text { Idade } \\
\text { gestacional de } \\
\text { diagnóstico* }\end{array}$ & $\begin{array}{c}\text { Idade gestacional } \\
\text { na coleta de } \\
\text { sorologia para o } \\
\text { B19* }\end{array}$ & Sorologia B19 & Causa provável & Desfecho* \\
\hline №1 & $25 / 04 / 2003$ & $22 \mathrm{~s} 2 \mathrm{~d}$ & $34 \mathrm{~s} 2 \mathrm{~d}$ & IgM-/IgG- & Hidrocefalia & $\begin{array}{l}\text { Vivo com alta } \\
\text { Internação 11d }\end{array}$ \\
\hline №2 & 09/06/2003 & $29 \mathrm{~s} 5 \mathrm{~d}$ & 30s 1d & IgM-/IgG+ & $\begin{array}{c}\text { Hipertensão } \\
\text { materna }\end{array}$ & $\begin{array}{c}\text { Óbito com 31s } \\
5 \mathrm{~d}\end{array}$ \\
\hline №3 & $18 / 06 / 2003$ & $32 \mathrm{~s} 2 \mathrm{~d}$ & $32 \mathrm{~s} 2 \mathrm{~d}$ & IgM-/IgG+ & Síndrome genética & Óbito com 33s \\
\hline No10 & $10 / 05 / 2004$ & $26 \mathrm{~s} 3 \mathrm{~d}$ & $27 \mathrm{~s} 4 \mathrm{~d}$ & IgM-/IgG+ & Não esclarecida & Óbito com 27s \\
\hline №12 & $02 / 08 / 2004$ & $27 \mathrm{~s} 1 \mathrm{~d}$ & $29 s$ & IgM-/IgG+ & Não esclarecida & Óbito com 29s \\
\hline №13 & $05 / 08 / 2004$ & $29 \mathrm{~s}$ & $31 \mathrm{~s} 1 \mathrm{~d}$ & $\begin{array}{l}\text { IgM borderline/ } \\
\text { IgG + }\end{array}$ & $\begin{array}{c}\text { Síndrome Down Provável } \\
\text { Parvovirus B19 }\end{array}$ & $\begin{array}{c}\text { Óbito com 31s } \\
6 \mathrm{~d}\end{array}$ \\
\hline №15 & $13 / 10 / 2004$ & $34 \mathrm{~s} 3 \mathrm{~d}$ & $34 \mathrm{~s} 3 \mathrm{~d}$ & IgM-/IgG+ & $\begin{array}{l}\text { Malf adenom } \\
\text { cística }\end{array}$ & $\begin{array}{l}\text { Vivo com alta } \\
\text { Internação } 5 d\end{array}$ \\
\hline №16 & $14 / 02 / 2005$ & $22 \mathrm{~s}$ & $26 \mathrm{~s}$ & IgM+/IgG+ & Parvovírus B19 & Desconhecido \\
\hline №17 & $15 / 02 / 2005$ & $20 \mathrm{~s}$ & $20 \mathrm{~s}$ & IgM bordeline/ IgG+ & Provável parvovírus B19 & Vivo com alta HFN revertida \\
\hline
\end{tabular}

* expresso em semanas (s) e dias (d). HFNI: hidropsia fetal não imune.

idade gestacional ( Tabela 4) e pelo número necessário para análise da amostra ter sido atingido em novembro de 2004. Cinco casos ocorreram em 2003, dez em 2004 e dois em 2005 (Tabelas 3 e 4).

Do total de 17 casos, o parvovírus B19 foi implicado como causador (definitivo ou provável) em 4 (23,5\%). Em um caso, a associação foi inequívoca pela história materna positiva de exantema na gestação, sorologia positiva (IgM e IgG) para 0 parvovírus B19 e rastreamento negativo para outras causas conhecidas de HF. Nos outros 3 casos o PB19 foi implicado como causa provável da HF devido ao resultado limítrofe da sorologia IgM. Destes três casos, em dois houve associação com síndrome de Down e no outro caso, a gestante residia na mesma região do caso confirmado de HF por PB19, além do fato da sorologia ter sido coletada no mesmo mês. Năo foi possível a realização de hibridização in situ nos três casos prováveis de HF por PB19.

A prevalência de anticorpos IgG antiparvovírus B19 em todos os 17 casos de hidropsia fetal foi de 72,2\% e a letalidade foi de $58,8 \%$ (Tabelas 3 e 4).

\section{DISCUSSÃ0}

A infecção pelo parvovírus B19 é considerada uma doença exantemática de ocorrência comum em crianças, com a maior parte dos casos acontecendo em menores de 15 anos de idade. No Brasil, o programa de erradicação do sarampo, iniciado em 1992, e o de controle de rubéola, reforçado a partir de 1994, auxiliaram a promover o diagnóstico laboratorial do eritema infeccioso ${ }^{12}$. Desta forma, a magnitude da infecção por parvovírus B19 na gestação tem sido melhor estudada, principalmente pela possibilidade de transmissão para 0 concepto e risco de morte fetal, aborto e hidropisia ${ }^{25819212426}$. Assim, 0 conhecimento do número de gestantes suscetíveis ao parvovírus B19 é importante para 0 acompanhamento pré-natal, especialmente nas primeiras 20 semanas de gestação, quando o risco de dano fetal causado por esse vírus é maior, embora a morte fetal por hidropisia possa acontecer até três meses após a infecção materna ${ }^{11}$.
A prevenção da infecção é difícil, pois ocorrem infecções inaparentes em $30 \%$ dos indivíduos e nos de casos de EI, 0 paciente não é mais contagioso quando há 0 surgimento do exantema típico. Não existe ainda uma vacina disponível licenciada para a prevenção da infecção entre as gestantes suscetíveis $^{1127}$.

A prevalência de anticorpos IgG antiparvovírus B19 em gestantes varia de acordo com a população estudada e 0 ano do estudo, mesmo dentro do Brasil. 0 valor (71,7\%) encontrado neste estudo foi semelhante aos registrados anteriormente na população em geral do Rio de Janeiro (73,7\%) e em gestantes da área urbana de Ribeirão Preto-SP (62,9\%) e na periferia de Belém$\mathrm{PA}(84 \%)$, indicando que cerca de $30 \%$ das gestantes permanecem suscetíveis à infecção ${ }^{3413}$. Isto é importante, pois na região metropolitana do Rio de Janeiro há um aumento no número de casos de eritema infeccioso em crianças a cada cinco anos ${ }^{17}$.

Verificamos que houve circulação do vírus em nosso meio em 2004 e 2005, demonstrada inequivocamente por dois casos de hidropisia fetal não-imune pelo parvovírus B19 confirmados laboratorialmente, sendo um do IFF e outro verificado em paciente da mesma região da cidade, no mesmo período do ano-verão 2004/200523. Um surto de eritema infeccioso, inclusive com acometimento de gestante, também foi relatado em novembro de 2004, em São José do Rio Preto-SP20. Durante as epidemias de EI são também descritas infecções em adultos, que podem se refletir no número de casos de hidropisia fetal não-imune atribuídos ao parvovírus B1919 26 .

Outros casos clínicos de infecção por B19 foram descritos na região metropolitana do Rio de Janeiro nos anos de $2004 \mathrm{e}$ 2005 (Noronha e cols ${ }^{15}$, Nascimento JP e cols ${ }^{25}$, Nascimento JP e cols ${ }^{14}$, Oliveira AS e cols ${ }^{19}$, Brasil Pe cols ${ }^{1}$, Passoni LFe cols ${ }^{18}$ ), indicando a existência provável de uma epidemia de EI. No entanto, não podemos fazer tal inferência através da nossa casuística em gestantes, pois apenas $11 \%$ das IgG negativas coletaram nova amostra de soro durante 0 terceiro trimestre da gestação, não sendo detectada soroconversão em nenhuma delas. 
Não encontramos, associação positiva de fatores conhecidos de risco para aquisição prévia de parvovirose humana como convívio com crianças e a presença de filhos menores de 10 anos no domicílio ${ }^{24}$. Apenas na variável número de gestações anteriores maior que um houve uma associação positiva para aquisição prévia de anticorpos antiparvovírus B19 e uma tendência de associação positiva quanto à variável idade maior que 20 anos. Provavelmente, a associação com estes fatores de risco teria sido verificada caso um número maior de gestantes fosse estudado.

Entre os dezessete casos de HF atendidos no IFF verificamos que o PB19 foi confirmado como causador em um e como provável causador em outros três. Notamos que em 2 casos houve associação com síndrome de Down o que pode tratar-se de uma coincidência ou não, pois o parvovírus B19 pode estar implicado como causador de malformações cardíacas levando ao desenvolvimento de $\mathrm{HF}^{28}$.

De qualquer forma, a maior parte dos casos atribuídos ao PB19 aconteceu a partir de agosto de 2004, período no qual houve circulação do vírus na cidade, sendo que a própria ocorrência de HF é um evento não usual na gravidez e a percentagem de casos de HF atribuídos ao PB19 (23,5\%) foi bem maior ao número de casos de HF atribuídos ao PB19 (10\%) em anos não epidêmicos para o parvovírus B1911 ${ }^{11}$.

Concluímos que a prevalência de anticorpos IgG antiparvovírus B19, encontrada em gestantes da área urbana da Cidade do Rio de Janeiro foi de 71,7\% indicando que cerca de $30 \%$ das grávidas são suscetíveis à infecção. Verificamos a circulação do vírus no município em 2005, corroborada por um caso de hidropsia fetal não-imune pelo parvovírus B19, confirmado sorologicamente, e outro confirmado por vínculo epidemiológico, detectados no mesmo mês e na mesma região geográfica da cidade.

\section{REFERÊNCIAS BIBLIOGRÁFICAS}

1. Brasil P, Souza RV, Serpa MJA, Lambert S, Maia SC, Nogueira RMR. Infecção por Parvovirus B19 em casos suspeitos de Dengue. Brazilian Journal of Infectious Diseases 9: S219, 2005.

2. Enders M, Weidner A, Zoellner I, Searle K, Enders G. Fetal Morbidity and mortality after acute human parvovirus B19 infection in pregnancy. Prospective evaluation of 1018 cases. Prenatal Diagnosis 24: 513-518, 2004.

3. Freitas RB, Gusmão SRB, Durigon EL, Linhares AC. Survey of parvovirus B19 infection in a cohort of pregnant women in Belém, Brazil. Brazilian Journal of Infectious Disease 3:6-14, 1999.

4. Gonçalves CV, Duarte G, Marcolin AC, Quintana SM, Covas DT, Costa JSD. Avaliação longitudinal da infecção por parvovírus B19 entre grávidas em Ribeirão Preto, SP, Brasil. Revista Brasileira de Ginecologia e Obstetrícia 25:317-321, 2003

5. Gratacos E, Torres PJ, Vidal J, Font J, Antolin E, Cararach E, Fortuny A. The incidence of human parvovirus B19 infection during pregnancy and its impact on perinatal outcome. The Journal of Infectious Diseases 171:1360-1363,1995.

6. Harger JH, Adler SP, Koch WC, Harger GE. Prospective evaluation of 618 pregnant women exposed to parvovirus B19: Risk and symptoms. Obstetrics and Gynecology 91:413-420, 1998.
7. Instituto Brasileiro de Geografia e Estatística. População do município do Rio de Janeiro.http://www.ibge.gov.br/cidades at/default.php Acesso em 25 de setembro de 2005.

8. Jensen IP, Thorsen P, Jeune P, Mooler BR, Vestergaard BT. An epidemic of parvovirus B19 in a population of 3596 pregnant women: a study of sociodemographic and medical risk factors. British Journal of Obstetrics and Gynaecology 7:637-643, 2000.

9. Maksheed M, Pacsa AS, Essa SS, Ahmed MA, Momen RA, Surkouh M. The prevalence of antibody to human parvovirus B19 in pregnant women in Kuwait. Acta Tropica 73:225-229, 1999.

10. Marinho TAS, Szrajbman AVS, Rodrigues NB, Faria RA, Setúbal S, Nascimento JP. Estudo da freqüência da infecção pelo parvovírus B19 em casos de doença exantemática no período de 1994 a 2004. Brazilian Journal of Infectious Disease 9: S73, 2005.

11. Markeson GR, Yancey MK. Parvovirus B19 infections in pregnancy. Seminars in Perinatology 22: 309-317, 1998.

12. Ministério da Saúde. Programa Nacional de erradicação do sarampo.<http://www.dtr2001.saude.gov.br/svs/epi/sarampo/sar00.htm> Acesso em 25 de setembro de 2005.

13. Nascimento JP, Buckley MM, Brown KE, Cohen BJ. The prevalence of antibodies to human parvovirus B19 in Rio de Janeiro, Brazil. Revista do Instituto de Medicina Tropical de São Paulo 32: 41-45,1990.

14. Nascimento JP, Gonçalves R, Santoro-Lopes G, Halpern M, Filgueiras R, Rocha P, Souza E, Carvalho DB, Brasil P, Matuck T. Human Parvovirus B19 infection in renal transplant recipients. In: Abstracs of the $2^{\text {nd }}$ European Congress of Virology, Espanha, p.319, 2004.

15. Noronha JT, Martins JC, Leal A, Pone MVS, Campos JMS, Barros ACMW, Garrido JRP, Pone SM, Nascimento JP. Parvovirus B19 associado ao HIV: Relato de caso. Revista da Sociedade Brasileira de Medicina Tropical 38 ( supl 1) :285, 2005.

16. Odland JO, Sergejeva IV, Ivaneev MD, Jensen IP, Stray-Pedersen B. Seropositivity of cytomegalovirus, parvovirus and rubella in pregnant women and recurrent aborters in Leningrad County, Russia. Acta Obstetricia et Gynecologica Scandinavica 80: 1025-1029, 2001.

17. Oliveira AS, Camacho LAB, Pereira ACM, Faillace TF, Setúbal S, Nascimento JP. Clinical and epidemiological aspects of human parvovirus B19 infection in an urban area in Brazil (Niterói City Area, State of Rio de Janeiro, Brazil). Memórias do Instituto Oswaldo Cruz 97:965-970, 2002.

18. Passoni LF, Nascimento JP, Sidi LC, Ribeiro SR, Mello VST. Dois casos de síndrome purpúrico-papular em luvas e meias por parvovírus B19. Brazilian Journal Infectious Diseases 9: S219, 2005.

19. Public Health Laboratory Service Working Party on Fifth Disease. Prospective study of human parvovirus B19 infection in pregnancy. British Medical Journal 300:1166-1170, 1990.

20. Secretaria de Estado de Saúde de São Paulo. Boletim Epidemiológico Paulista (BEPA) Investigação de Surto de Doença Exantemática em Municípios da Diretoria Regional de Saúde XXII- São José do Rio Pretosetembro a dezembro de 2004. <http://www.pauster.saude.sp.gov.br/ extras/bepa1204.pdf>. acesso em 25 de setembro de 2005.

21. Silva ARA, Alzeguir JCL, Costa MCLF, Tristão MAP, Nogueira SA, Nascimento JP. Hidropisia fetal. Análise de 80 casos. Revista Brasileira de Ginecologia e Obstetrícia 3:143-147, 2005.

22. Skjoldebran-Sparre L, Fridell E, Nyman M, Wahren B. A prospective study of antibodies against parvovirus B19 in pregnancy. Acta Obstetricia et Gynecologica Scandinavica 75:336-339, 1996.

23. Valente MB, Neiva MG, Luiz SC, Victal SHS, Teixeira N, Burla M, Nascimento JP. Hidropsia fetal de causa infecciosa. Jornal Paranaense de Pediatria 6:47, 2005.

24. Valeur-Jensen AK, Pedersen CB, Westergaard T, Jensen IP, Lebech M, Andersen PK, Aaby P, Pedersen BN, Melbye M. Risk factors for parvovirus B19 infection in pregnancy. The Journal of the American Association 281:1099-1105, 1999. 
25. Vieira IF, Andrada-Serpa MJ, Waltrick V, Escada R, Tavares ICF, Wagner S, Nascimento JP. Anemia grave relacionada à infecção por parvovírus B19 em pacientes com Síndrome de Imunodeficiência Humana Adquirida (AIDS) . Brazilian Journal of Infectious Diseases 9: S142, 2005.

26. Yaegashi N, Ninuma T, Chisaka S, Uehara K, Okamura O, Shinkawa 0, Tsunoda A, Moffatt S, Sugamura K, Yajima A. Serologic study of human parvovirus B19 infection in pregnancy in Japan. Journal of Infection 38:30-35, 1999.
27. Young NS, Brown KE. Parvovirus B19. The New England Journal of Medicine 350: 586-597, 2004

28. Wang X, Zhang G, Lui F, Han M, Xu D, Zang Y. Prevalence of human parvovirus B19 DNA in cardiac tissues of patients with congenital heart diseases indicated by nested PCR and in situ hybridization. Journal of Clinical Virology 31: 20-24, 2004 